\title{
混合动力技术发展现状及专利分析
}

\section{Development Status and Patent Analysis of Hybrid Power Technology}

\author{
张广宇 \\ Guangyu Zhang \\ 国家知识产权局专利局专利审查协作北京中心 中国·北京 100160 \\ Patent examination Cooperation (Beijing) Center of the Patent Office, CNIPA, Beijing, 100160, China
}

摘 要: 混合动力汽车既有传统内燃机汽车的特性, 又有新型电动汽车的特性。论文介绍了混合动力汽车的分类及主流混合 动力系统的结构及特点, 并从专利申请的角度分析了国际汽车企业的发展现状。

\begin{abstract}
Hybrid electric vehicles have the characteristics of both traditional internal combustion engine vehicles and new electric vehicles. This paper introduces the classification of hybrid electric vehicles and the structure and characteristics of the mainstream hybrid system, and analyzes the development status of domestic and foreign automobile enterprises from the perspective of patent application.
\end{abstract}

关键词: 混合动力; 专利; 新能源

Keywords : hybrid power;patent;new energy

DOI : $10.36012 /$ peti.v2i3.2074

\section{1 引言}

近年来, 汽车产业快速发展, 随之而来能源、环境和交通 安全等问题也越来越受到关注。国家法规对汽车排放与油耗 限值的要求越来越严格, 传统的内燃机无法同时满足排放与 油耗的要求。当前纯电动汽车受到价格、续航能力、充电条件 等方面的限制, 还不能大规模发展应用。而混合动力汽车, 即 采用传统的内燃机和电动机组合在一辆汽车上做驱动力。混 合动力汽车既有传统内燃机汽车的特性, 又有新型电动汽车 的特性, 具有动力响应快, 油耗低、排放低、不需要额外充电 装置、行驶里程长等诸多优势, 因此, 近年来, 混合动力汽车 成为现阶段各大汽车厂商积极研发的重点。

\section{2 混合动力汽车的分类}

目前, 混合动力汽车主要有串联式、并联式、混联式 3 种 工作形式。

\section{1 串联式结构}

电机直接带动车轮, 发动机不直接参与驱动, 只负责输 出机械能。串联式驱动系统由发动机、电动机、控制器、传动 系统以及电池组等构成, 发动机产生的机械能直接传送到发 电机, 发电机将机械能转换为电能, 电动机通过蓄电池的电
能或者直接利用发电机产生的电能驱动车辆。串联式结构的 发动机仅与发电机直接连接, 发动机与汽车传动系统无机械 连接, 可以控制发动机在最低油耗区工作, 具有发动机热效 率高、节油效果明显的优点。

\section{2 并联式结构}

发动机和电动机是 2 个独立的动力系统, 汽车在行驶过 程中可以由发动机或者电动机单独提供动力, 也可以由 2 个系 统共同提供动力, 车辆在上坡、加速时的负载最大, 这时候需要 两者共同工作, 发动机照常运作, 电池输出电能给电动机, 从 而协同发动机输出转矩到变速箱, 用来满足所需负载。和串联 式相比, 并联式结构要求发动机与道路负荷耦合, 而且与电池 的配合需要相当复杂的技术, 所以系统控制难度比较高。

\section{3 混合式结构}

综合了串联式结构和并联式结构,这种结构可以实现单 串联或者单并联结构, 而且还可以实现串并联共同运行。在 汽车低速行驶时, 汽车以串联方式运行; 当汽车高速行驶时 以并联方式运行。发动机单独驱动时, 和传统汽车的运转方 式相同, 使发动机处于经济转速区域, 从而更好地发挥出电 动机驱动工作模式和发动机驱动模式的优势, 达到降低能耗 的目的 ${ }^{[1 \sim 3]}$ 。 


\section{3 主流混合动力系统对比分析}

(1)丰田第二代混合动力系统 THS-IV 采用发电机与发动 机通过单排行星排同轴布置的结构 (见图 1 ), 发电机与太阳 轮固定连接, 发动机与行星架固定连接, 行星排系统的动力 通过齿圈输出; 驱动电机与行星排机构平行布置。行星排与 驱动电机分别输出的动力通过输出轴汇合, 最终由差速器传 递给车轮。电动机驱动系统可以单独工作, 在汽车处于急速 工况、低速运行时, 发动机停止工作, 电动机驱动汽车行驶, 仅在电动机驱动系统提供的驱动力不足或电池组亏电时, 发 动机才恢复运转给汽车提供动力, 并给电池组充电, 降低了 油耗, 提高了燃油经济性, 同时减少了有害气体排放。

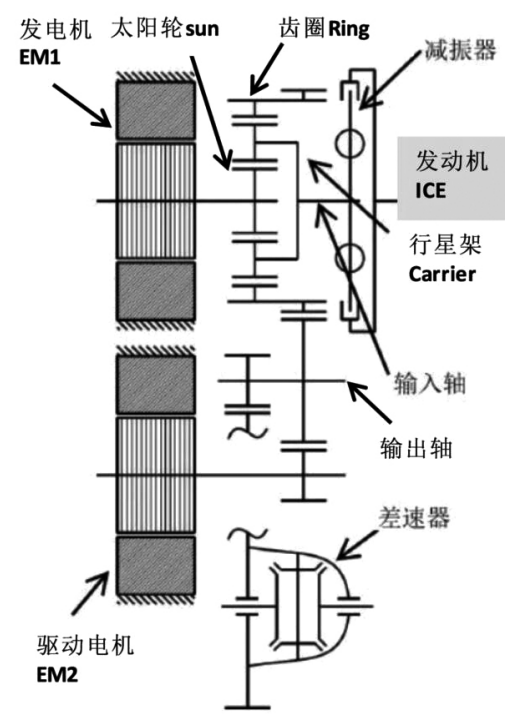

图 1 THS-IV 结构布局

(2)本田 i-MMD 系统主要由阿特金森循环发动机、驱动 电机、发电机、e-CVT 及锂电池组组件组成( 见图 2)。其中, 发动机与驱动电机各只有一档, 且发动机档位与驱动电机 档位并联布置。驱动电机通过减速机构可直接驱动车轮; 发 动机输出曲轴与发电机通过减速齿轮并联后, 经过离合器 与减速机构耦合, 进而驱动车轮。虽然从技术层面来说, 本 田i-MMD 混合动力系统不及丰田的先进, 但从实用性以及 易普及程度等方面来看也有着自己的优势, 具有结构简单、 占用空间小以及制造成本低的优势。

(3)比亚迪 DM 混合动力系统具有前后 2 个电机, 其中前 电机通过变速箱与发动机并联驱动前轮, 后电机直接驱动后 车轮, 前后轴动力共同输出 (见图 3 )。通过用后电机单独驱 动后车轮, 可以不用通过传动轴将发动机的动力传递到后 轴, 即实现了全时四驱, 又空出更大的空间来容纳更大容量
的电池组, 更高的电池度数提高了纯电驱动模式的续航里 程, 并且发动机和前、后双电机能够在爬坡、急加速等高负荷 状态下共同对外输出, 动力响应快, 且续航里程长 ${ }^{[4]}$ 。

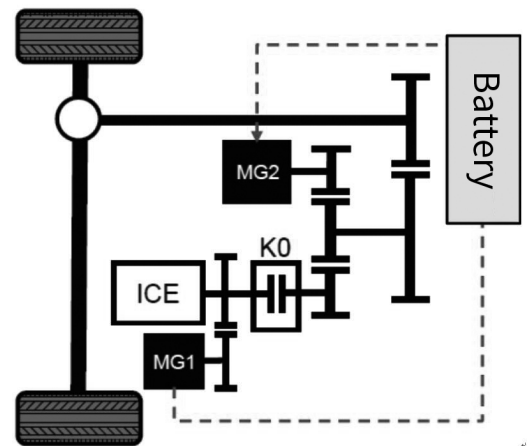

图 2 本田 i-MMD 结构布局

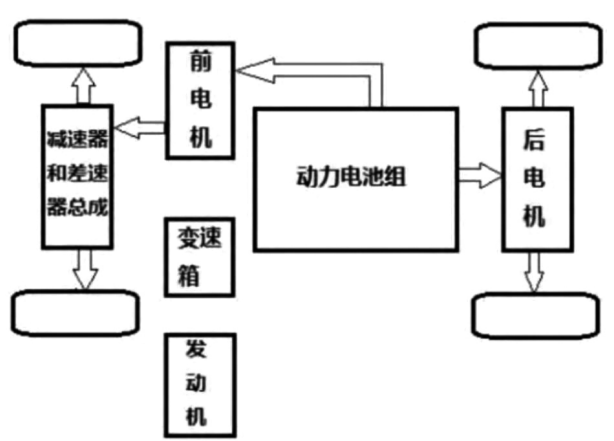

图 3 比亚迪 DM 结构布局

\section{4 混合动力汽车专利申请分析}

为了更加深入了解各大汽车厂商在混合动力汽车方面 的研究现状, 将混合动力技术的专利申请检索结果以申请人 进行篮选和统计, 能够得到混合动力技术的专利申请排名, 如图 4 所示。

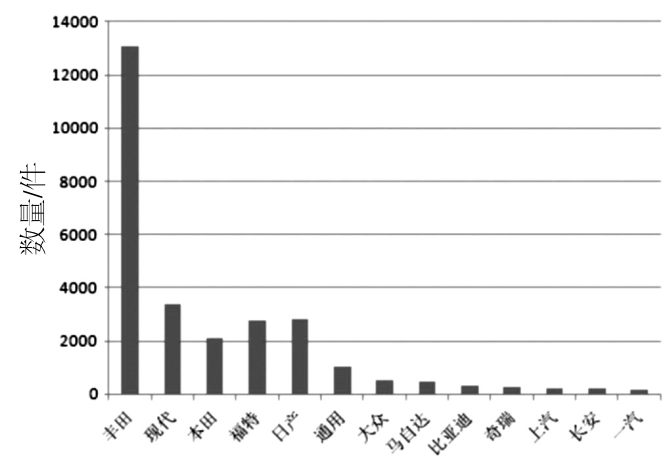

图 4 主要厂商专利申请数量排名

自 1997 年丰田普锐斯问世, 丰田相继推出了 4 代油电 混合动力系统 THS, 均采用了混合式结构。丰田公司在全球 范围内申请了 13000 余件专利, 形成了一个庞大而严密的 
专利保护网。韩国现代汽车、日本本田技研、美国福特汽车、 日本日产汽车也投入了大量的研究精力, 申请了几千件专 利, 中国主要车企中, 比亚迪、奇瑞、上汽、长安等虽然也紧随 其后, 开始在混合动力领域追赶国际大厂的研发步伐。

\section{5 结语}

“十三五” 以来, 中国的新能源汽车开始快速发展, 国家 和地方都对新能源汽车行业出台了许多利好政策。如“关于 2016-2020 年新能源汽车推广应用财政支持政策的通知” “锂离子电池行业规范公告管理暂行办法”等, 这些政策的出 台在一定程度上保证和促进了新能源汽车的发展。混合动力 电动汽车有效解决了传统汽车高能耗、高排放的问题, 是未 来汽车工业相对一段时间发展的方向。然而, 当前的混合动
力电动汽车在发展过程还存在续航能力差、发动机燃烧效率 低等问题, 严重影响到混合动力电动汽车的发展。因此, 需要 加快混合动力电动汽车的关键技术研发, 促进新能源汽车行 业的发展。

\section{参考文献}

[1] 付偣, 张永, 胡志林. 本田混合动力发动机技术[J].汽车文摘,2020 (6):12-15.

[2] 王海峰. 浅谈未来新能源汽车的技术发展趋势[J].科学技术创 新,2020(13):158-159.

[3] 黄家贵. 混合动力电动汽车关键技术分析 [J]. 科学技术创新, 2020(14):60-61.

[4] 杨斌.丰田凯美瑞混合动力汽车探究[J].农家参谋,2020(5):190.

常关闭的情况下, 各个回路才能正常投入使用, 开关箱配置 像电梯三角钥匙才能打开的专用锁具, 由持证值班电工保管 使用, 从源头上禁止了私拉乱接现象的发生。

(5)对于配电箱锁具成摆设的问题, 则配置如电梯三角锁 一样的锁具, 全部通用, 由持证值班电工专门保管使用, 能够 有效杜绝锁具损坏和成摆设的通病。 需要监理单位的安全管理人员会同建设单位和施工单位的 相关人员, 严格按照临电施工组织设计的要求, 对临电设施 检查和验收, 按照要求做好验收记录形成资料保存备查, 对 不符合方案要求的设施, 坚决不得投入使用, 同时对相关责 任人进行严肃处理, 以敲响安全的警钟。

(3)对于 “一机一箱一漏一闸”执行力不足, 私拉乱接的问 题,一是用制度做保证, 二是在技术上采取措施, 把二级箱和 三级箱进行可操作的技术改造, 在箱内部的每个回路增加一 套由安全电压控制的交流接触器, 所有的开启和关闭由控制 按钮来完成, 并且有相应回路开启的信号指示灯, 为减少箱 体的体积, 控制按钮的开启按钮选用带灯按钮; 把开关箱做 成一个完全密封的箱体, 同时, 交流接触器的容量务必与该 回路用电器的容量完全匹配; 使配电箱对外仅存控制按钮和 信号指示灯, 人人均可以安全操作。

(4)对于私拉乱接,线缆敷设不走出线孔的问题,则在开 关箱上做文章, 在开关箱门上的适当位置配置微动开关, 用 以对所有回路的控制回路进行控制, 只有在保证开关箱门正

\section{4 结语}

本文的重点是将二级和三级配电箱做成黑洞一样的专 用箱, 等于在原来的制度(软件)防火墙的基础上, 又加上一 道技术 (硬件) 防火墙, 严禁除持证电工以外的其他人员开 启, 非正常开启后会造成整个配电箱的各个回来被自动关闭 而不能开启, 操作面板上只有带灯控制按钮和停止控制按 钮, 像家电一样供用电人员操作使用, 安全方便可靠。同时, 从源头上彻底解决了临电工作中的一些危险和通病的发生, 进一步提高建设工程施工现场的安全等级, 为建设工程有序 按计划推进提供基础性的后勤保障。

\section{参考文献}

[1] JGJ 46-2005 施工现场临时用电技术规范[S].

[2] 陈正一浅谈建筑工程施工现场临时用电安全管理[J]. 建筑安 全,2020(5):29-30.

[3] 徐润.浅谈房屋建筑工程施工现场临时用电安全监督管理[J].建 筑安全,2014(10):66-69. 